\title{
Sasa quelpaertensis Phenylpropanoid Derivative Suppresses Lipopolysaccharide-induced Nitric Oxide Synthase and Cyclo-oxygenase-2 Expressions in RAW 264.7 Cells
}

\author{
Ji-Young MoON,,$^{a, b}$ Eun-Jin YANG, ${ }^{a}$ Sang Suk KIM, ${ }^{b}$ Ji-Yong KANG, ${ }^{a}$ \\ Gi-Ok KIM, ${ }^{a}$ Nam Ho LEE, ${ }^{*}, b, \#$ and Chang-Gu HYUN ${ }^{a}, \#$ \\ aBio-Convergence Center, Jeju Technopark, Jeju 690-121, Korea, and ${ }^{b}$ Department of Chemistry, \\ Jeju National University, Jeju 690-756, Korea
}

(Received June 1, 2010; Accepted March 2, 2011)

\begin{abstract}
3-O-p-Coumaroyl-1-(4-hydroxy-3,5-dimethoxyphenyl)-1-O- $\beta$-D-gulcopyranosylpropanol (ESQ10) is a naturally occurring phenylpropanoid derivative isolated from Sasa quelpaertensis (Gramineae). In the present study, we discovered that ESQ10 inhibits nitric oxide (NO) and prostaglandin $\mathrm{E}_{2}\left(\mathrm{PGE}_{2}\right)$ production in lipopolysaccharide (LPS) stimulated RAW 264.7 macrophages. ESQ10 attenuated LPS-induced synthesis of inducible nitric oxide synthase (iNOS) and cyclooxygenase-2 (COX-2) in parallel and inhibited LPS-induced interleukin-6 production, as determined by an enzyme-linked immunosorbent assay in the macrophages. The mechanism of the antiinflammatory action of ESQ10, i.e., suppression of nuclear factor $(\mathrm{NF})-\kappa \mathrm{B}$ and mitogen-activated protein kinase activation, has been documented. However, ESQ10 could not influence LPS-mediated I $\kappa \mathrm{B}-\alpha$ degradation and extracellular signal-regulated kinase/c-Jun amino-terminal kinase phosphorylation at concentrations of up to $373 \mu \mathrm{M}$. To test the potential application of ESQ10 as a topical material, we also conducted a 3-(4,5-dimethylthiazol-2-yl)-2,5-diphenyltetrazolium bromide assay on human HaCaT keratinocytes as well as human dermal fibroblast cells. In this assay, ESQ10 did not induce cytotoxicity. Taken together, the results suggest that ESQ10 may be considered an antiinflammatory candidate for treating inflammatory and skin diseases.
\end{abstract}

Key words_— cyclooxygenase-2 (COX-2); inducible nitric oxide synthase (iNOS); inflammation; phenylpropanoid; Sasa quelpaertensis

\section{INTRODUCTION}

Inflammation is one of the most important host defense mechanisms against tissue injuries and invading pathogens. However, although acute inflammation is a beneficial process, particularly in response to infectious pathogens, chronic inflammation is an undesirable phenomenon that can ultimately lead to inflammatory diseases ${ }^{1)}$ such as asthma, ${ }^{2,3)}$ rheumatoid arthritis, ${ }^{4,5)}$ inflammatory bowel disease, ${ }^{6)}$ psoriasis, ${ }^{7)}$ bronchitis, ${ }^{8,9)}$ gastritis, ${ }^{10)}$ and multiple sclerosis. ${ }^{11)}$ Inflammation is a central feature in many pathologic conditions and is mediated by a variety of soluble factors and cellular signalling events such as nuclear transcription factor kappa-B $(\mathrm{NF}-\kappa \mathrm{B})$ and mitogenactivated protein kinases (MAPKs) pathways. NF$\kappa \mathrm{B}$ regulates various genes involved in cell survival as well as immune and acute-phase inflammatory responses. In response to proinflammatory stimuli, NF$\kappa \mathrm{B}$ is activated and the IKK signalosome complex

\footnotetext{
*e-mail: namho@cheju.ac.kr

\# These authors contributed equally to this work.
}

rapidly phosphorylates $\mathrm{I} \kappa \mathrm{Bs}$. The resulting free NF$\kappa \mathrm{B}$ then translocates to the nucleus, where it binds to $\kappa \mathrm{B}$-binding sites in the promoter regions of target genes and induces the transcription of proinflammatory mediators such as inducible nitric oxide synthase (iNOS), cyclooxygenase-2 (COX-2), interleukin-6 (IL-6), tumour necrosis factor-alpha (TNF- $\alpha$ ), IL$1 \beta$, and IL-8. ${ }^{12-14)}$ The MAPKs [ (extracellular signalregulated kinase (ERK), p38, and c-Jun amino-terminal kinase $(\mathrm{JNK})]$ react to extracellular stimuli and control various cellular activities, including gene expression, mitosis, differentiation, and cell survival/ apoptosis. MAPKs regulate inflammatory and immune responses, and their signalling pathways are involved in lipopolysaccharide (LPS) -induced COX-2 and iNOS expression in macrophages. ${ }^{15,16)}$ Thus NF$\kappa \mathrm{B}$, iNOS, COX-2, and IL-6 have been exploited as molecular targets in the discovery and development of drugs for inflammatory-related diseases. ${ }^{17-19)}$

There have been many attempts to derive new antiinflammatory and anticancer agents from natural compounds. Traditional remedies derived from herbs or medicinal plants have been considered safe, less 
toxic, and readily available, even though their mechanisms of action are mostly still ambiguous. Thus uncovering the molecular mechanism underlying the antiinflammatory function of natural products may be a good strategy for identifying new therapeutic agents. Previously, our research group documented the antiinflammatory properties of various medicinal plants. ${ }^{20-24)}$

During our ongoing screening program designed to identify the antiinflammatory potential of natural compounds, we isolated 3-O-p-coumaroyl-1-(4-hydroxy-3,5-dimethoxyphenyl ) -1-O- $\beta$-D-gulcopyranosylpropanol (ESQ10) from the leaves of Sasa quelpaertensis using activity-directed fractionation and characterized its structural identity using spectroscopy ( ${ }^{1} \mathrm{H}-$ and ${ }^{13} \mathrm{NMR}$, IR, MS), as published previously. ${ }^{25)}$ However, there has been no report on its biological activity or mechanism of action, although we previously reported that ESQ10 significantly inhibits mushroom tyrosinase. ${ }^{25)}$ Therefore, as a prelude to revealing the mechanisms underlying the antiinflammatory effects of ESQ10, we evaluated variations in inflammatory proteins and cytokine expression in vitro in the presence of ESQ10. Moreover, we determined how ESQ10 exhibits antiinflammatory activity.

\section{MATERIALS AND METHODS}

Chemicals and Reagents ESQ10 was isolated essentially as described previously. ${ }^{25)}$ Dulbecco's modified Eagle's medium (DMEM) and fetal bovine serum (FBS) were obtained from Invitrogen-Gibco (Grand Island, NY, USA) . Enzyme-linked immunosorbent assay (ELISA) kits for prostaglandin $\mathrm{E}_{2}$ $\left(\mathrm{PGE}_{2}\right)$ and IL-6 were purchased from R\&D Systems, Inc. (St. Louis, MO, USA) and BD Biosciences (San Diego, CA, USA). Anti-I $\kappa \mathrm{B}-\alpha$, anti-phosphorylated $\mathrm{I} \kappa \mathrm{B}-\alpha$ (anti-p-I $\kappa \mathrm{B}-\alpha)$, anti-JNK, anti-phosphorylated JNK (anti-p-JNK), anti-ERK1/2, and anti-phosphorylated ERK1/2 (anti-p-ERK1/2) mouse or rabbit antibodies were purchased from Cell Signaling Technology (Beverly, MA, USA). PD98059 (a specific inhibitor of ERK1/2), SP600125 (a specific inhibitor of JNK), and pyrollidine dithiocarbamate (PDTC, a specific inhibitor of NF- $\kappa$ B) were purchased from Calbiochem (San Diego, CA, USA). All other reagents were purchased from Sigma-Aldrich Chemical Co. (St. Louis, MO, USA). ESQ10 was prepared as in a previous study. ${ }^{25}$ )
RAW 264.7 Cell Culture RAW 264.7 cells were obtained from the Korean Cell Line Bank (KCLB; Seoul, Korea) and maintained at subconfluence in a $95 \%$ air, $5 \% \mathrm{CO}_{2}$ humidified atmosphere at $37^{\circ} \mathrm{C}$. The medium for routine subcultivation was DMEM supplemented with FBS (10\%), penicillin (100 units/ $\mathrm{ml})$, and streptomycin $(100 \mu \mathrm{g} / \mathrm{ml})$. Cells were counted with a hemocytometer, and the number of viable cells was determined by trypan blue dye exclusion.

Nitric Oxide Determination Nitric oxide accumulation was used as an indicator of NO production in the cell culture medium and was determined in the Griess reaction. The culture supernatant $(100 \mu \mathrm{l})$ was mixed with the same volume of Griess reagent $[1$ $\%$ sulphanilamide and $0.1 \% \mathrm{~N}$-(1-naphthyl) -ethylenediamine dihydrochloride in $5 \%$ phosphoric acid] for $10 \mathrm{~min}$, and the absorbance was measured at 540 $\mathrm{nm}$. Sodium nitrite $\left(\mathrm{NaNO}_{2}\right)$ was used for the standard curve $(1-100 \mu \mathrm{M})$.

Detection of PGE $_{2}$ and IL-6 in Supernatant

Sandwich ELISA was used to determine the inhibitory effects of ESQ10 $47 \mu \mathrm{M}, 94 \mu \mathrm{M}, 186 \mu \mathrm{M}$, and $373 \mu \mathrm{M}$ on the production of the cytokines $\mathrm{PGE}_{2}$ and IL-6 in LPS-treated RAW 264.7 cells. RAW 264.7 cells were stimulated for $24 \mathrm{~h}$ before the supernatant was harvested and assayed according to the manufacturer's protocol for the relevant ELISA kit. Results from 3 independent experiments were used for statistical analysis.

Western Blot Analysis The RAW 264.7 cells $\left(1.5 \times 10^{5}\right.$ cells $\left./ \mathrm{ml}\right)$ were preincubated for $18 \mathrm{~h}$ and then treated with LPS $(1 \mu \mathrm{g} / \mathrm{ml})$ plus aliquot sample for $24 \mathrm{~h}$. After incubation, the cells were washed twice with cold PBS. Whole-cell lysates $(25 \mu \mathrm{g})$ were separated on $10 \%$ sodium dodecyl sulphate-polyacrylamide gel electrophoresis (SDS-PAGE) and electrotransferred to a polyvinylidene fluoride (PVDF) membrane (BIO-RAD, HC). The membrane was incubated for $24 \mathrm{~h}$ with $5 \%$ skim milk and then incubated with a specific primary antibody $(1: 2500)$ at room temperature for $2 \mathrm{~h}$. The membrane was washed 4 times with TTBS and incubated for $30 \mathrm{~min}$ with a peroxidase-conjugated secondary antibody $(1: 5000)$ at room temperature. Finally, the proteins on the membrane were detected using the WESTZOL Western Blot Detection System (iNtRON, Gyeonggi, Korea) .

3- (4,5-Dimethylthiazol-2-yl) -2,5-diphenyltetrazo- 
lium Bromide Assay for Cell Viability Cell viability was determined in the 3-(4,5-dimethylthiazol-2-yl) 2,5-diphenyltetrazolium bromide (MTT) assay. RAW 264.7 cells were cultured in 96-well plates for 18 $\mathrm{h}$, followed by treatment with LPS $(1 \mu \mathrm{g} / \mathrm{ml})$ in the presence of various concentrations of the sample. After 24-h incubation, MTT was added to the medium for $4 \mathrm{~h}$. Finally, the supernatant was removed, and the formazan crystals were dissolved in DMSO. Absorbance was measured at $540 \mathrm{~nm}$. The percentage of cells showing cytotoxicity relative to the control group was determined.

Statistical Analysis Student's $t$-test and oneway ANOVA were used to determine statistically significant differences between the values in the various experimental and control groups. Data are expressed as mean \pm standard error (S.E.M.), and the results are taken from at least three independent experiments performed in triplicate.

\section{RESULTS}

ESQ10 Reduces NO Production and Inhibits iNOS Formation It is well established that RAW 264.7 cells, a mouse macrophage cell line, induce the expression of COX-2 and iNOS, which produce large amounts of $\mathrm{PGE}_{2}$ and $\mathrm{NO}$, respectively, when activated with LPS. Therefore the modulation of macrophage-mediated inflammatory responses is emerging as a promising new therapeutic approach against inflammatory diseases. ${ }^{26-29)}$ LPS, a major cell wall component of Gram-negative bacteria, induces a strong innate and adaptive immune response and was used to elicit increased NO synthesis. Since the half-life of NO is very short, we used nitrite production as an indicator of NO released by LPS-activated macrophages. Compared with normal macrophages, NO production increased $>15$-fold in LPS-activated macrophages, to $17.1 \pm 0.7$ vs. $1.10 \pm 0.05, p<0.01$ (Fig. 1A) . ESQ10 reduced LPS-induced NO production in a dose-dependent manner. At ESQ10 concentrations of $47 \mu \mathrm{M}, 94 \mu \mathrm{M}, 186 \mu \mathrm{M}$, and $373 \mu \mathrm{M}$, the production of NO by LPS-treated macrophages decreased by $31.6 \% \quad(11.8 \pm 2.4, p<0.01), 43.7 \%$ $(9.63 \pm 2.5, p<0.05), 55.3 \% \quad(7.73 \pm 0.9, p<0.01)$, and $76.2 \%(4.12 \pm 2.3, p<0.01)$, respectively, as compared with LPS-treated macrophages not treated with ESQ10 (Fig. 1A). DMSO, the vehicle control, had no effect on NO production, reconfirming its immunologic inertness. Furthermore, ESQ10 itself caused minimal change in NO production in resting macrophages. In parallel, the potential cytotoxicity of ESQ10 was evaluated in the MTT assay after incubating cells for $24 \mathrm{~h}$ in the presence and absence of LPS. However, cell viability was negligibly affected at the concentrations used ( $47 \mu \mathrm{M}, 94 \mu \mathrm{M}, 186 \mu \mathrm{M}$, and 373 $\mu \mathrm{M}$ ) to inhibit NO (Fig. 1A). Thus the inhibitory effects of ESQ10 were not attributable to cytotoxicity.

To elucidate further the mechanisms by which ESQ10 inhibited NO production in LPS-activated macrophages, we analyzed its effect on LPS-induced iNOS gene expression in macrophages. Under normal conditions, RAW 264.7 cells expressed undetectable levels of iNOS mRNA, but iNOS mRNA levels increased markedly after $24 \mathrm{~h}$ of LPS stimulation (Fig. $1 \mathrm{~B})$. With the addition of ESQ10 $(47 \mu \mathrm{M}-373 \mu \mathrm{M})$, dose-dependent inhibition of iNOS expression was observed, indicating that ESQ10 modulates iNOS expression.

ESQ10 Reduces the Release of Inflammatory Mediators and Proinflammatory Cytokines in Macrophages $\mathrm{PGE}_{2}$, the most important inflammatory product of COX-2, was quantified in the supernatants of LPS-treated RAW 264.7 macrophages. Cells were preincubated with ESQ10 for $1 \mathrm{~h}$, after which they were stimulated with LPS $1 \mu \mathrm{g} / \mathrm{ml}$ for $24 \mathrm{~h}$. Neither LPS nor the sample were treated in the control group. Cell culture media were collected, and $\mathrm{PGE}_{2}$ levels determined. Compared with unstimulated macrophages, the $\mathrm{PGE}_{2}$ level increased dramatically by 4 fold in LPS-stimulated macrophages. With the addition of ESQ10 $47 \mu \mathrm{M}, 94 \mu \mathrm{M}, 186 \mu \mathrm{M}$, and $373 \mu \mathrm{M}$, a dose-dependent reduction in $\mathrm{PGE}_{2}$ was observed to $4.7 \pm 3.5 \%, 13.2 \pm 3.2 \%, 27.7 \pm 7.4 \%$, and $36.7 \pm 5.7$ $\%$, respectively (Fig. 2A). To determine the mechanism by which ESQ10 reduces LPS-induced $\mathrm{PGE}_{2}$ production, we studied the ability of ESQ10 to influence the LPS-induced expression of COX-2. The addition of LPS resulted in a clearly defined increase in COX-2 expression which was markedly attenuated in a dose-dependent fashion when treated with ESQ10 (Fig. 2B), corroborating that ESQ10 induces a decrease in COX-2, which translates into a dramatic decrease in $\mathrm{PGE}_{2}$. As expected, the reference compounds, dexamethasone (COX-2 inhibitor) and 2amino-4-methyl pyridine (iNOS inhibitor) potently inhibited $\mathrm{PGE}_{2}$ and $\mathrm{NO}$ production at $20 \mu \mathrm{M}$, respectively.

When macrophages are stimulated with LPS, they 
(A)

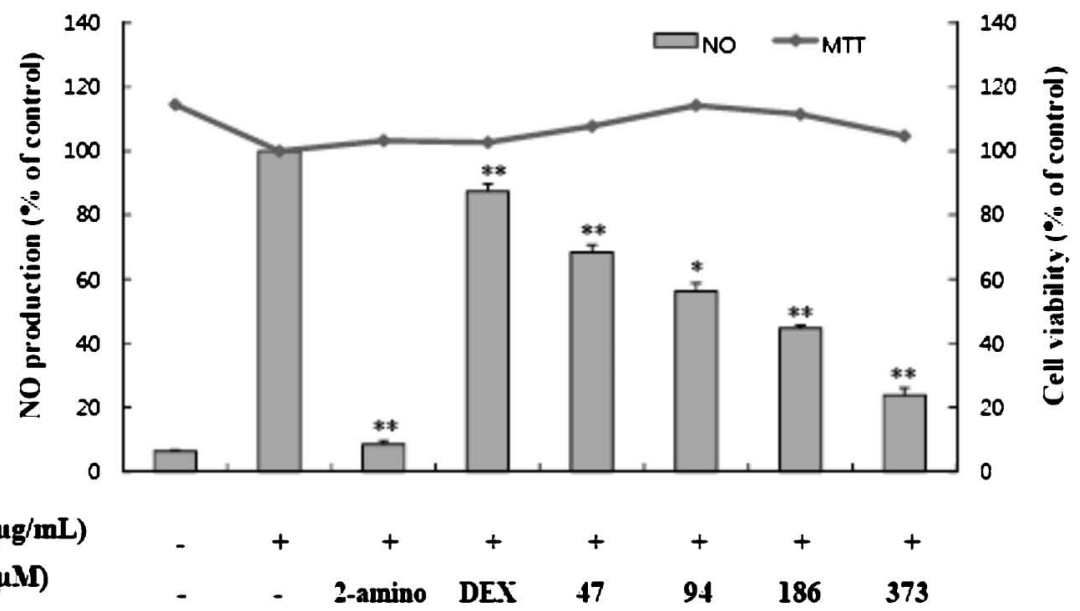

(B)

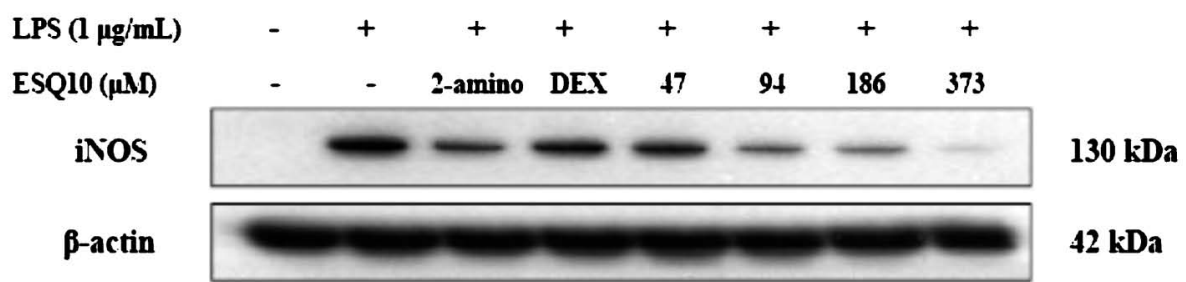

Fig. 1. Effects of ESQ10 on Nitric Oxide (A) Production and Levels of iNOS Protein (B) in LPS-stimulated RAW 264.7 Cells The cells were stimulated with $1 \mu \mathrm{g} / \mathrm{ml}$ of LPS alone or with LPS plus various concentrations ( $47 \mu \mathrm{M}, 94 \mu \mathrm{M}, 186 \mu \mathrm{M}$, and $373 \mu \mathrm{M})$ of ESQ10, 2-amono-4methylpyridine (2-amino; $20 \mu \mathrm{M})$, and dexamethasone (DEX; $20 \mu \mathrm{M})$ for $24 \mathrm{~h}$. Nitric oxide production was determined using the Griess reagent method. Cell viability was determined in the $24-\mathrm{h}$ culture of cells stimulated with LPS $(1 \mu \mathrm{g} / \mathrm{ml})$ in the presence of ESQ10. Whole-cell lysates $(25 \mu \mathrm{g})$ were prepared, and the protein was subjected to $10 \%$ SDS-PAGE. Expression of iNOS and $\beta$-actin were determined by Western blotting. $\beta$-Actin was a loading control. The data represent the mean \pm S.D. of triplicate experiments. Cytotoxicity was determined using the MTT method. Values are presented as the mean \pm S.E.M. of triplicate experiments. ${ }^{*} p<0.05 ;{ }^{*} p<0.01$.

secrete several proinflammatory cytokines, including IL-1 $\beta$, IL-6, and TNF- $\alpha$. Accordingly, we examined the effect of ESQ10 on the LPS-induced expression of IL-6. LPS induced a dramatic increase in IL-6 expression, which ESQ10 decreased in a dose-dependent manner (Fig. 3).

ESQ10 Treatment Has No Effect on LPS-induced I $\boldsymbol{B}$ B and MAPK Phosphorylation When resting, in unstimulated macrophages, the heterodimeric NF$\kappa \mathrm{B}$ complex is sequestered in the cytoplasm as an inactive precursor complexed with an inhibitory protein, I $\kappa \mathrm{B}$. LPS-mediated activation of NF- $\kappa \mathrm{B}$ correlates with the hyperphosphorylation of $\mathrm{I} \kappa \mathrm{B}-\alpha$ and its subsequent degradation. ${ }^{30}$ Therefore we examined the levels of phosphorylated $\mathrm{I} \kappa \mathrm{B}$ using immunoblot analysis. As expected, treatment with LPS enhanced the phosphorylation of $\mathrm{I} \kappa \mathrm{B}$, as evidenced by the increased binding of phosphospecific $\mathrm{I} \kappa \mathrm{B}$ antibody as compared with that in controls (Fig. 4). However, Fig. 4 shows that LPS-induced $\mathrm{I} \kappa \mathrm{B}-\alpha$ degradation is not significantly blocked by pretreatment with ESQ10.

MAPKs play a critical role in the regulation of cell growth and differentiation, and they control cellular responses to cytokines and stress. In addition, MAPKs play a critical role in the modulation of NF$\kappa \mathrm{B}$ activity. To investigate the molecular mechanism of NF- $\kappa$ B inhibition by ESQ10 in LPS-stimulated RAW 264.7 cells, we studied the inhibition of the phosphorylation of ERK1/2 and JNK. RAW 264.7 cells were pretreated with ESQ10 at the indicated concentrations for $30 \mathrm{~min}$ and then stimulated with LPS $1 \mu \mathrm{g} / \mathrm{ml}$ for $30 \mathrm{~min}$. The total cell lysates were then probed with phosphospecific antibodies for ERK1/2 and JNK. Phosphorylation of ERK1/2 and JNK increased in cells treated with LPS alone. No changes in the expression of phosphorylated and nonphosphorylated ERK and JNK were observed in cells treated with LPS or LPS and ESQ10 (Fig. 5). These results suggest that the suppression of phosphorylation of MAPKs might not be involved in the inhibitory effect of ESQ10 on LPS-stimulated NF- $\kappa$ B activation in RAW 264.7 cells. 


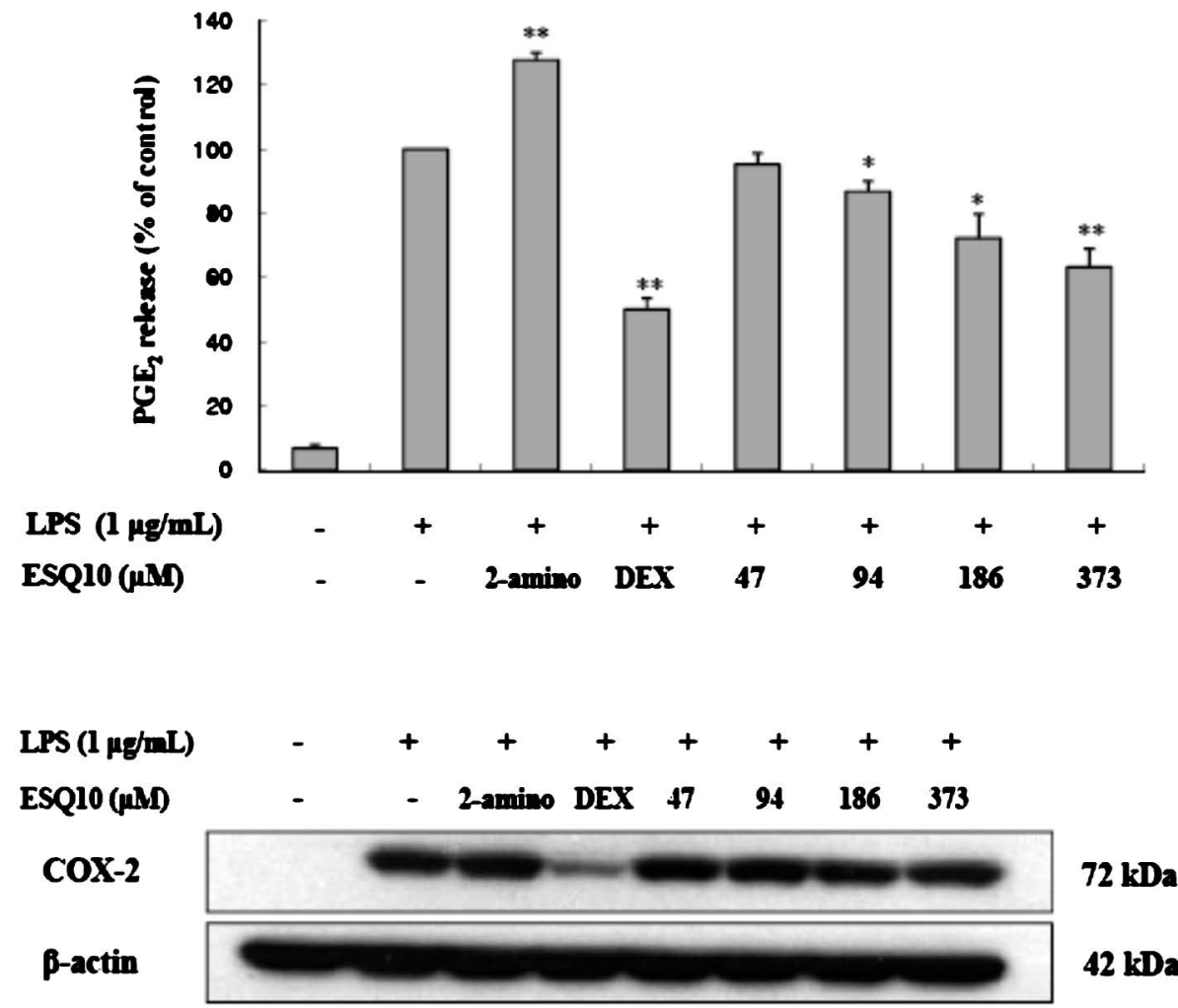

Fig. 2. Effects of ESQ10 on PGE 2 Production and Level of COX-2 Protein in LPS-stimulated RAW 264.7 Cells

The cells were stimulated with $1 \mu \mathrm{g} / \mathrm{ml}$ of LPS alone or with LPS plus various concentrations ( $47 \mu \mathrm{M}, 94 \mu \mathrm{M}, 186 \mu \mathrm{M}$, and $373 \mu \mathrm{M}$ ) of ESQ10, 2-amono-4 methylpyridine (2-amino; $20 \mu \mathrm{M})$, and dexamethasone (DEX; $20 \mu \mathrm{M})$ for $24 \mathrm{~h}$. $\mathrm{PGE}_{2}$ produced and released into the culture medium was assayed using the EIA method. The data represent the mean \pm S.D. of triplicate experiments. Whole-cell lysates $(25 \mu \mathrm{g})$ were prepared, and the protein was subjected to $10 \%$ SDS-PAGE. Expression of COX-2 and $\beta$-actin were determined by Western blotting. $\beta$-Actin was a loading control. Values are presented as the mean \pm S.E.M. of triplicate experiments. ${ }^{*} p<0.05 ;{ }^{* *} p<0.01$.

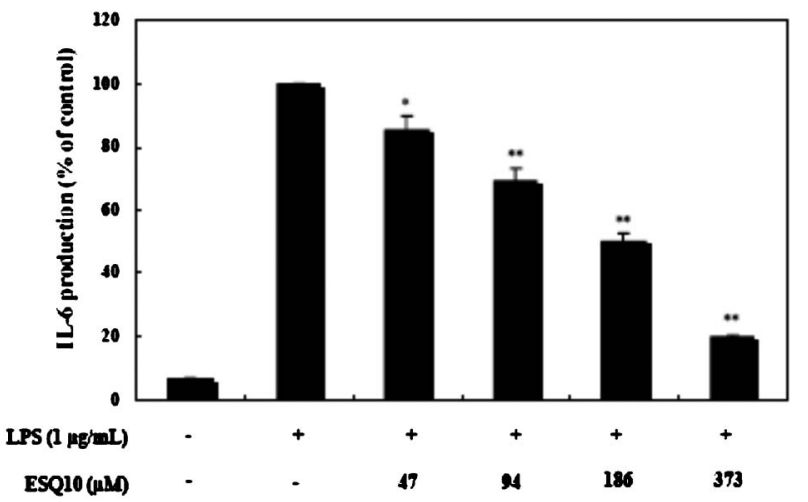

Fig. 3. Effects of ESQ10 on IL-6 Production in LPS-stimulated RAW 264.7 Cells

The cells were stimulated with $1 \mu \mathrm{g} / \mathrm{ml}$ of LPS alone or with LPS plus various concentrations $(47 \mu \mathrm{M}, 94 \mu \mathrm{M}, 186 \mu \mathrm{M}$, and $373 \mu \mathrm{M})$ of ESQ10 for $24 \mathrm{~h}$. IL-6 produced and released into the culture medium was assayed using the ELISA method.

\section{DISCUSSION}

Inflammatory processes play a critical role in the pathogenesis of many human diseases. Overproduction of inflammatory mediators by macrophages,

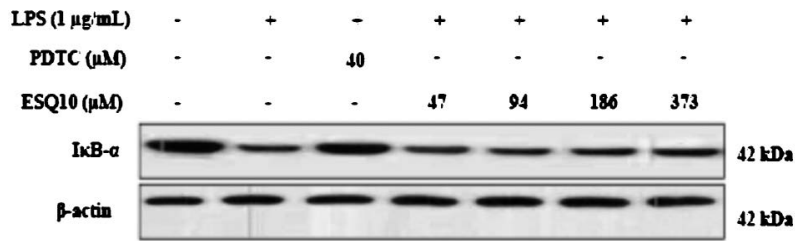

Fig. 4. Effects of ESQ 10 on the Degradation of $\mathrm{I} \kappa \mathrm{B}-\alpha$ in LPSstimulated RAW 264.7 Cells

RAW 264.7 cells $\left(1.0 \times 10^{6}\right.$ cells $\left./ \mathrm{ml}\right)$ were stimulated with LPS $(1 \mu \mathrm{g} /$ $\mathrm{ml})$ in the presence of ESQ10 $(47 \mu \mathrm{M}, 94 \mu \mathrm{M}, 186 \mu \mathrm{M}$, and $373 \mu \mathrm{M})$ or PDTC $(40 \mu \mathrm{M})$ for $15 \mathrm{~min}$. Whole-cell lysates $(30 \mu \mathrm{g})$ were prepared, and the protein was subjected to $12 \%$ SDS-PAGE. Expression of $\mathrm{I} \kappa \mathrm{B}-\alpha$ and $\beta$-actin was determined by Western blotting. $\beta$-Actin antibody was the loading control.

such as cytokines and NO, has been implicated in inflammatory diseases such as asthma, ${ }^{2,3}$ rheumatoid arthritis, ${ }^{4,5)}$ and inflammatory bowel disease. ${ }^{6)}$ In this study, we investigated the inhibitory effects of ESQ10 on LPS-induced NO production and expression of iNOS and COX-2 in RAW 264.7 cells. ESQ10 significantly inhibited LPS-induced NO production in a dose-dependent manner. ESQ10 strongly inhibited 


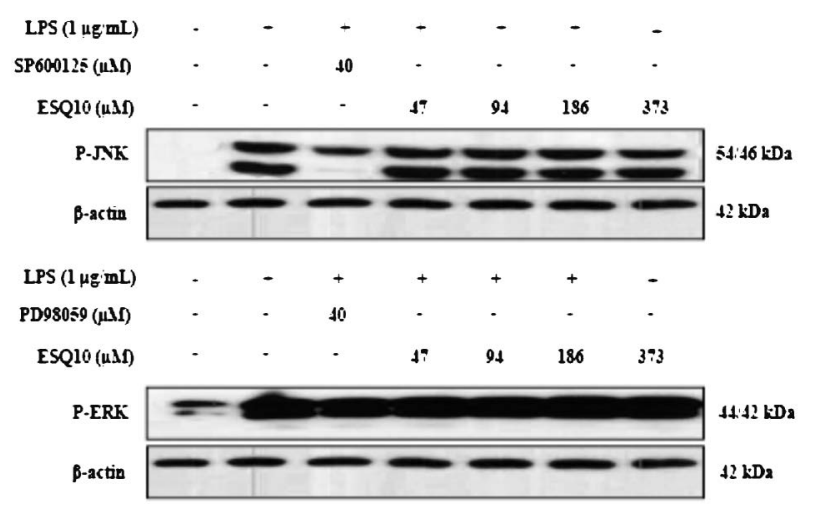

Fig. 5. Effects of ESQ10 on the Phosphorylation of p-JNK and p-ERK in LPS-stimulated RAW 264.7 Cells

RAW 264.7 cells $\left(1.0 \times 10^{6}\right.$ cells $\left./ \mathrm{ml}\right)$ were stimulated with LPS $(1 \mu \mathrm{g} /$ $\mathrm{ml})$ in the presence of ESQ10 $(47 \mu \mathrm{M}, 94 \mu \mathrm{M}, 186 \mu \mathrm{M}$, and $373 \mu \mathrm{M})$, SP600125 (40 $\mu \mathrm{M}$ for $30 \mathrm{~min}$ ), or PD98059 $(40 \mu \mathrm{M}$ for $20 \mathrm{~min})$. Whole-cell lysates $(30 \mu \mathrm{g})$ were prepared, and the protein was subjected to $12 \%$ SDSPAGE. Expression of $\mathrm{p}$-JNK, $\mathrm{p}$-ERK, and $\beta$-actin were determined by Western blotting. $\beta$-Actin antibody was the loading control.

LPS-induced NO production in RAW 264.7 cells, with an $\mathrm{IC}_{50}$ value of $175.0 \mu \mathrm{M}$. These inhibitory effects may not be related to their cytotoxic effects since no effects were observed on the viability of RAW 264.7 cells at concentrations of up to $373 \mu \mathrm{M}$. This inhibitory effect of NO production could be related to the gene expression of iNOS, since ESQ10 inhibited iNOS protein in RAW 264.7 cells. ESQ10 also inhibited LPS-induced COX-2 expression. These results show that ESQ10 could interfere with LPS-induced signalling involving the production of proinflammatory molecules. However, our data showed that the expression of COX-2 was less sensitive than that of iNOS to ESQ10. This could account for the higher sensitivity of iNOS gene transcription to ESQ10 compared with that of COX-2.

Since LPS-induced iNOS and COX-2 expression is primarily regulated by NF- $\kappa \mathrm{B}$, we partially examined the effect of ESQ10 on the LPS-induced activation of $\mathrm{NF}-\kappa \mathrm{B}$. Several studies showed that antiinflammatory agents inhibit the activation of NF- $\kappa \mathrm{B}$ by preventing $\mathrm{I} \kappa \mathrm{B}$ degradation. $\mathrm{I} \kappa \mathrm{B} \alpha$ specifically binds and masks the nuclear translocation signals of p50 and p65, thereby preventing the nuclear translocation of the NF- $\kappa$ B heterodimer. ${ }^{12,30)}$ Reddy and Reddanna ${ }^{31)}$ showed that chebulagic acid prevents the induced degradation of $\mathrm{I} \kappa \mathrm{B} \alpha$ by diverse stimuli and therefore interferes with a common step in the signalling cascade leading to the activation of NF- $\kappa \mathrm{B}$ and MAPK. Lee et $a l .{ }^{32)}$ have also demonstrated that preventing $\mathrm{I} \kappa \mathrm{B}$ degradation by carabrol contributes to the inacti-

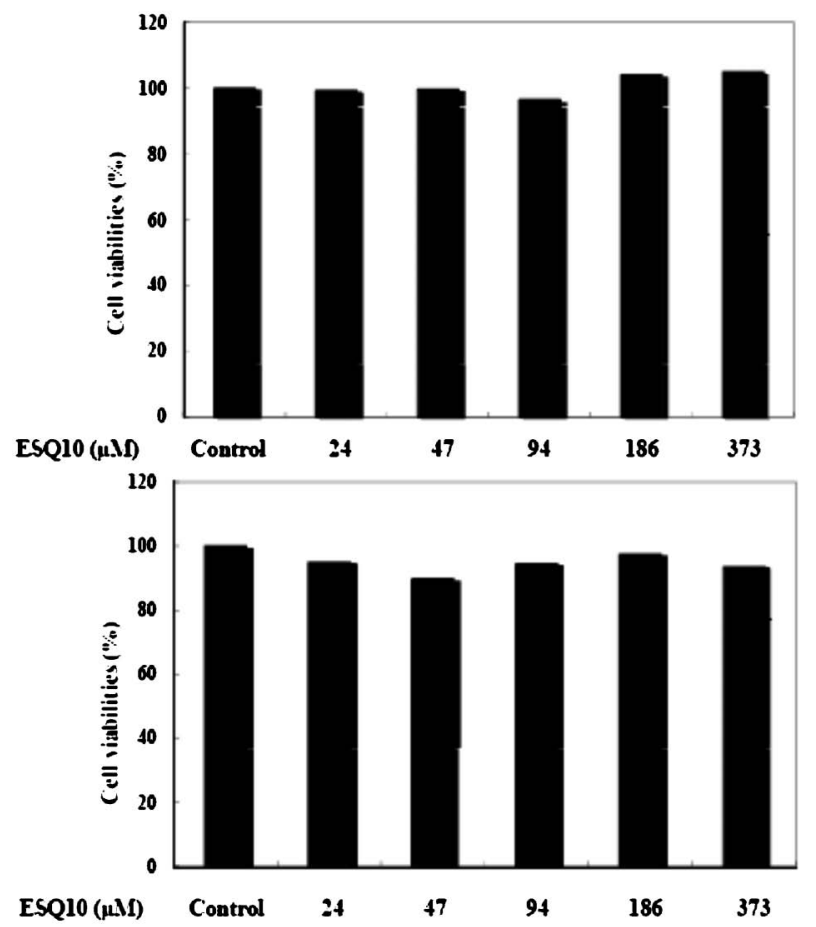

Fig. 6. Assessment of ESQ10 Cytotoxicity in Human Dermal Fibroblasts (A) and $\mathrm{HaCaT}$ Keratinocytes (B)

An MTT assay was performed after incubating human dermal fibroblasts and $\mathrm{HaCaT}$ keratinocytes. $\mathrm{HaCaT}$ cells were treated with various concentrations of ESQ10 for $24 \mathrm{~h}$ at $37^{\circ} \mathrm{C}$ in a $5 \% \mathrm{CO}_{2}$ atmosphere. Absorbance was measured at $570 \mathrm{~nm}$ using a spectrophotometer (Power Wave; Bio-Tek, Winooski, VT, USA).

vation of NF- $\kappa \mathrm{B}$ (p50) in the antiinflammatory reaction in RAW 264.7 cells. However, ESQ10 did not inhibit the expression of iNOS/COX-2 and NO and $\mathrm{PGE}_{2}$ production through the prevention of $\mathrm{I} \kappa \mathrm{B}$ degradation. MAPKs play a critical role in the regulation of cell growth and differentiation and in the control of cellular responses to cytokines and stressors. Moreover, MAPKs are involved in the LPS-induced signalling pathway via which iNOS is expressed. In the present study, we also assessed whether the phosphorylation of MAPKs can be induced by ESQ10. However, treatment with ESQ10 had no effect on LPS-induced JNK and ERK phosphorylation. This result suggests that JNK and ERK are not involved in the inhibition by ESQ10 of LPS-stimulated NF- $\kappa$ B binding in RAW 264.7 cells.

Finally, to test the use of ESQ10 as a topical material, we performed an MTT assay with human cell lines, HaCaT keratinocytes and dermal fibroblasts. In these assays, ESQ10 did not induce any severe adverse reactions in the human cell lines (Fig. 6). Therefore we conclude that ESQ10 can be used as a therapeutic agent for inflammatory diseases via 
$\mathrm{I} \kappa \mathrm{B}$, a JNK- and ERK-independent pathway.

Acknowledgments This research was partially supported by Programs for the Regional Strategic Industries and, the Regional Innovation System (JEJU SASA PROJECT), which are managed by the Ministry of Knowledge and Economy, Republic of Korea.

\section{REFERENCES}

1) Kim J. Y., Park S. J., Yun K. J., Cho Y. W., Park H. J., Lee K. T., Eur. J. Pharmacol., 584, 175-184 (2008).

2) Agrawal D. K., Shao, Z., Curr. Allergy Asthma Rep., 10, 39-48 (2010).

3) Zhang X., Köhl J., Expert Rev. Clin. Immunol., 6, 269-277 (2010).

4) Kukar M., Petryna O., Efthimiou P., Biologics, 3, 443-457 (2009).

5) Goronzy J. J., Weyand C. M., Arthritis Res. Ther., 11, 249 (2009).

6) Fichtner-Feigl S., Fuss I. J., Preiss J. C., Strober W., Kitani A., J. Clin. Invest., 115, 3057-3071 (2005).

7) Kunz M., Curr. Drug Discov. Technol., 6, 231 -240 (2009).

8) Simpson J. L., Phipps S., Gibson P. G., Pharmacol Ther., 124, 86-95 (2009).

9) Desai D., Brightling C., Otolaryngol. Clin. North Am., 43, 123-130 (2010).

10) Fox J. G., Wang T. C., J. Clin. Invest., 117, 60-69 (2007).

11) Aktas O., Kieseier B., Hartung H. P., Trends Neurosci., 33, 140-152 (2010).

12) Edwards M. R., Bartlett N., W., Clarke D., Birrell M., Belvisi M., Johnston S. L., Pharmacol. Ther., 121, 1-13 (2009).

13) Ghosh S., Hayden M. S., Nat. Rev. Immunol., 8, 837-848 (2008).

14) Wong E. T., Tergaonkar V., Clin. Sci., 116, 451-465 (2009).

15) Brown M. D., Sacks D. B., Handb. Exp. Pharmacol., 186, 205-235 (2008).

16) Ji R. R., Gereau R. W. 4th, Malcangio M., Strichartz G. R., Brain Res. Rev., 60, 135-148 (2009).
17) Murakami A., Ohigashi H., Int. J. Cancer, 121, 2357-2363 (2007).

18) Ding C., Cicuttini F., Li J., Jones G., Expert Opin. Investig. Drugs, 18, 1457-1466 (2009).

19) Feldmann M., J. Clin. Invest., 118, 3533-3536 (2008).

20) Yang E. J., Moon J. Y., Lee J. S., Koh J., Lee N. H., Hyun C. G., J. Biomed. Biotechnol., doi: $10.1155 / 2010 / 715739$ (2010).

21) Yoon W. J., Moon J. Y., Song G., Lee Y. K., Han M. S., Lee J. S., Ihm B. S., Lee W. J., Lee N. H., Hyun C. G., Food Chem. Toxicol., 48, 1222-1229 (2010).

22) Yoon W. J., Ham Y. M., Yoo B. S., Moon J. Y., Koh J., Hyun C. G., J. Biosci. Bioeng., 107, 429-438 (2009).

23) Yoon W. J., Kim S. S., Oh T. H., Lee N. H., Hyun C. G., Lipids., 44, 471-476 (2009).

24) Yang E. J., Yim E. Y., Song G., Kim G. O., Hyun C. G., Interdisc. Toxicol., 2, 101-105 (2009)

25) Sultana N., Lee N. H., Bull. Korean Chem. Soc., 30, 1729-1732 (2009).

26) Murakami A., Forum Nutr., 61, 193-203 (2009) .

27) Yang E. J., Moon J. Y., Kim M. J., Kim D. S., Kim C. S., Lee W. J., Lee N. H., Hyun C. G., J. Zhejiang Univ. Sci. B, 11, 315-322 (2010).

28) Ci X., Ren R., Xu K., Li H., Yu Q., Song Y., Wang D., Li R., Deng X., Inflammation, 33, 126-136 (2010)

29) Harasstani O. A., Moin S., Tham C. L., Liew C. Y., Ismail N., Rajajendram R., Harith H. H., Zakaria Z. A., Mohamad A. S., Sulaiman M. R., Israf D. A., Inflamm. Res., doi: 10.1007/S0011-010-0182-8 (2010).

30) Ferreiro D. U., Komives E. A., Biochemistry, 49, 1560-1567 (2010).

31) Reddy D. B., Reddanna P., Biochem. Biophys. Res. Commun., 381, 112-117 (2009).

32) Lee H. J., Lim H. J., Lee da Y., Jung H., Kim M. R., Moon D. C., Kim K. I., Lee M. S., Ryu J. H., Biochem. Biophys. Res. Commun., 391, 1400-1404 (2010). 